\title{
Um guia para a análise crítica multimodal
}

\author{
Kamila Bossato Fernandes \\ https://orcid.org/0000-0002-9828-021X \\ I - UFC. \\ Fortaleza (CE), Brasil
}

LEDIN, P.; MACHIN, D.

Doing Visual Analysis: from theory

to practice. London, Thousand

Oaks, New Delhi, Singapore: Sage

Publications, 2018. 208 p.

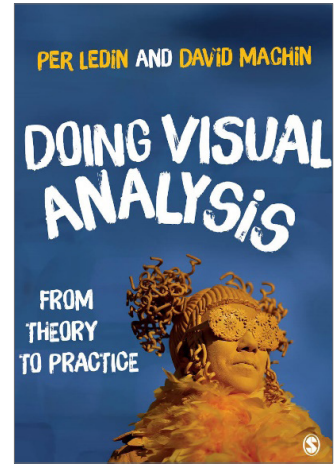

Resumo: Nesta resenha, apresentamos o livro de Per Ledin e David Machin (2018) que expõe um modelo de análise visual abrangendo diferentes tipos de material semiótico, desde fotografias, documentos e vídeos até embalagens, design de espaços e apresentações de dados. Com base em conceitos da semiótica social e da análise crítica do discurso, os autores propõem um modelo de análise de viés crítico, para compreender não só como os sentidos são construídos a partir de cada um desses materiais, mas também que sentidos são produzidos, tendo em vista os contextos sociais e as disputas de poder que condicionam as visões de mundo. A obra constitui um bom guia introdutório para pesquisadores que se interessam pela análise semiótica, por demonstrar, com exemplos práticos, a aplicabilidade do modelo teórico-metodológico e sua relação com questões de investigação.

Palavras-chave: análise visual; semiótica social; discurso; prática social.

Abstract: A guide to critical multimodal analysis - In this review, we present the book written by Per Ledin and David Machin (2018), which brings a visual analysis model that covers different types of semiotic material, including photographs, documents, and videos, as well as packaging, space design, and data presentations. Based on concepts of social semiotics and critical discourse analysis, the authors propose a critical framework model to understand not only how each semiotic material produce meaning, but also what meanings are produced within the social contexts and power struggles that condition worldviews. The book is a good introductory guide for researchers interested in semiotic analysis, for demonstrating 
the applicability of the theoretical-methodological model with practical examples and its relation to research questions.

Keywords: visual analysis; social semiotics; discourse; social practice.

Por mais que a experiência social vivida na contemporaneidade tenha se tornado cada vez mais multimodal, ainda são poucas as iniciativas de investigação que visam analisar, sistematicamente, materiais de comunicação visual, indo além do texto escrito. Isso se dá porque as ferramentas de análise, em geral, são pouco práticas ou se limitam a descrições amparadas em avaliações estéticas, que têm valor, mas não abrangem todas as dimensões de produção de sentidos. Foi com o intuito de preencher essa lacuna e propiciar um conjunto de ferramentas aplicável à mais vasta gama de materiais semióticos que Ledin e Machin desenvolveram o livro Doing Visual Analysis, lançado em 2018 pela Sage Publications.

Neste livro, Ledin e Machin (2018) demonstram a aplicabilidade de conceitos e ferramentas da análise crítica do discurso multimodal (MCDA, em inglês), a partir de diferentes exemplos práticos, para responder diretamente a questões de investigação. Para tanto, os autores decidiram analisar tanto objetos mais recorrentes nos estudos de comunicação visual, como as fotografias, quanto outros incomuns, como as embalagens, o design de espaços e os vídeos promocionais. A intensão não é limitar as discussões a esses objetos, mas tomá-los como ponto de partida para demonstrar as potencialidades das ferramentas de análise e suas possíveis combinações, para que possam ser aplicadas a qualquer outro objeto multimodal.

Para os autores, a análise semiótica desses materiais e de tantos outros permite que capturemos não só a forma como esses materiais foram construídos (e a que se destinam), mas também a maneira como experimentamos esses elementos no cotidiano, até chegar a compreender como moldam o que fazemos e pensamos sobre eles e sobre a estrutura social como um todo (LEDIN; MACHIN, 2018, p. 4).

A relação entre os materiais da comunicação visual e o mundo social é central na visão de Ledin e Machin (2018), aspecto que os autores demonstram com exemplos práticos, como ao comparar interpretações sobre capas de catálogos de uma loja de decoração, que, ao longo do tempo, incorporou valores não só estéticos, mas também sociais, que remetem a diferentes contextos. Afinal, explicam, os sentidos são estabelecidos não apenas pelos materiais semióticos em si mesmos, e por suas aplicabilidades potenciais (affordances) - que também devem ser consideradas em qualquer análise -, mas pelas relações com ideias e valores de determinado tempo e espaço, sendo passíveis de reinterpretações a partir do momento em que qualquer uma dessas variáveis seja alterada.

Com isso em vista, os autores propõem perguntas de investigação sobre a produção de sentido a partir de certos parâmetros ou cânones hegemônicos, de modo a ser possível identificar recorrências, diferenças e até subversões desses padrões, também construídas 
socio-historicamente. O conhecimento prévio dos contextos sociais e do repertório que envolve a produção e o consumo dos materiais semióticos é essencial para qualquer análise.

Ledin e Machin (2018) apresentam como principais inspirações de sua perspectiva de análise obras da semiótica social (KRESS; VAN LEEUWEN, 2001, 2006) e da análise crítica do discurso (FAIRCLOUGH, 1995; VAN DIJK, 1998), enfatizando a influência da linguística sistêmico-funcional de Halliday (1985). Mas argumentam que, muitas vezes, as análises que seguem tais pressupostos se restringem a impor conceitos que acabam por apenas demonstrar como os elementos visuais funcionam, o que leva ao risco de fazer crer que todas as formas de comunicação visual são da mesma ordem (LEDIN; MACHIN, 2018, p. 12), suprimindo suas diferenças.

Assim, para chegar a uma proposta de análise dos materiais semióticos, de um lado, Ledin e Machin (2018) aderem à ideia da análise crítica do discurso sobre a relevância da relação indissociável entre discurso e prática social, com vistas a desvendar relações de poder e, com isso, ideologias implícitas na produção discursiva; e, de outro, assumem a importância de se considerar a abrangência da comunicação visual, e, sobretudo, o papel da multimodalidade na produção de sentidos, com todas as escolhas e motivações que implicam essa construção, como sustenta a semiótica social. Chega-se ao modelo da MCDA, que os autores buscam aplicar ao longo do livro.

Cabe destacar que tal modelo já havia sido desenvolvido em obra anterior, por Machin e Mayr (2012), também sob a proposta de apresentar uma visão introdutória de análise semiótica multimodal. A diferença para o livro mais recente, entretanto, é o caráter prático: na nova obra, optou-se por uma linguagem mais concisa, que remete diretamente à aplicabilidade do modelo de análise a objetos empíricos.

A obra tem nove capítulos, incluindo a conclusão, e seis deles são dedicados especificamente a explorar exemplos de análise prática, seguindo sempre o mesmo padrão: introdução sobre o objeto a ser analisado, discussão sobre a relação entre o objeto e a produção de discursos e sentidos, a análise propriamente dita e sugestões de perguntas de investigação. Os objetos são apresentados com algum grau de complexidade: por exemplo, no caso da fotografia, foram incluídas discussões e análises sobre fotojornalismo e fotografia artística. São também apresentadas análises que levam em conta o formato de documentos, embalagens, design de espaço, vídeos promocionais e apresentação de dados.

Mais exemplos surgem nas conclusões, tanto para ressaltar a diversidade dos materiais semióticos que nos rodeiam e que podem ser analisados, como para demonstrar a complexidade que os envolvem, exigindo do pesquisador um conhecimento que vai muito além da mera capacidade descritiva ou de fazer uma avaliação estética. Como todo discurso, a comunicação visual é produto de relações de poder, refletindo certos valores e ideias que representam certa posição sociopolítica dominante de um determinado local e tempo. A análise de um site de vendas de produtos esportivos, por exemplo, precisa levar em conta as relações de gênero, bem como as visões sobre tendências do neoliberalismo, como o individualismo e o autocontrole; precisa vislumbrar, ainda, como os sentidos são 
construídos, não apenas para vender determinados produtos, mas para garantir a adesão do consumidor à marca, pelo afeto.

Evidentemente, o livro não esgota as questões de investigação, nem os caminhos e as ferramentas que podem ser aplicadas em diversos materiais semióticos. Até porque, como os próprios autores admitem nas conclusões, toda a visão ali apresentada tem um determinado ponto de partida, que é ocidentalizado, cristão, capitalista (LEDIN; MACHIN, 2018, p. 193), condicionantes que impedem uma visão total. Pesquisadores de fora do eixo Estados Unidos-Grã-Bretanha-Europa, ao se depararem com materiais semióticos diversos do seu entorno, certamente podem apresentar outras questões e agregar outros conceitos ao modelo de análise proposto.

De todo modo, trata-se de uma obra interessante, ao destacar o quanto os diferentes materiais semióticos que nos rodeiam são significativos, na construção de sentidos sobre o mundo, tal qual o conhecemos, e o quanto é necessário que esses sentidos sejam criticamente decodificados, esmiuçados, a ponto de que possamos compreender os interesses que estão por trás da sua construção, nas disputas de poder que revestem o social e dão sentido a ele. Mais do que isso, a obra é válida ao demonstrar a viabilidade de se fazer análise sistemática e crítica de materiais multimodais diversos, ampliando a gama de possibilidades de investigação para além do domínio da linguagem ou dos media, tornando-se, portanto, um importante contributo para as ciências sociais como um todo.

Kamila Bossato Fernandes é doutoranda na Universidade Federal do Ceará e professora de telejornalismo.

kamila.fernandes@ufc.br

\section{Referências}

FAIRCLOUGH, N. Discurso e mudança social. Brasília: Editora UnB, 2001.

HALLIDAY, M. A. K. An introduction to functional grammar. London: Edward Arnold Press, 1985.

KRESS, G.; VAN LEEUWEN, T. Multimodal Discourse. New York: Bloomsbury Academic, 2001.

Reading Images: The Grammar of Visual Design. London, New York: Routledge, 2006.

LEDIN, P., MACHIN, D. Doing Visual Analysis: from theory to practice. London, Thousand Oaks, New Delhi, Singapore: Sage Publications, 2018.

MACHIN, D.; MAYR, A. How to do Critical Discourse Analysis - A multimodal introduction. Los Angeles, London, New Delhi: Sage Publications, 2012.

VAN DIJK, T. A. Ideology, a Multidisciplinary Approach. London, Thousand Oaks: Sage Publications, 1998. 